\title{
RESEÑA DEL LIBRO TRES MIRADAS AL MÉXICO DE HOY. DE ALBERTO AZIZ NASSIF, ENRIQUE VALENCIA LOMELÍ Y JORGE ALONSO SÁNCHEZ (2020). MÉXICO: CÁTEDRA INTERINSTITUCIONAL - UNIVERSIDAD DE GUADALAJARA
}

José Javier Capera

Universidad Iberoamericana-México.

caperafigueroa@gmail.com

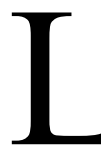

os complejos tiempos que vivimos ante el suceso demoledor de la emergencia global del Covid-19, nos muestran las debilidades sistémicas de las instituciones y la incapacidad de los Estados y gobiernos modernos por dar garantías, rutas y esquemas que sirvan como insumos estratégicos para hacerle frente a las crisis estructurales de nuestros tiempos. Parte de esta realidad, no es ajena a las otras formas y expresiones radicales de pandemias que se han vivido históricamente: despojo, saqueo, re-colonización, genocidios y exterminios físico, cultura, étnico, racial, ideológico, ecológico y social entre otros.

La pandemia de las violencias, el despojo en los territorios y el asesinato sistemático de actores, grupos y colectivos de forma individual y comunitaria, responde a otra expresión profunda de vivir en medio del terrorismo de Estado y la incapacidad gubernamental, para impulsar alternativas y rutas, en concreto, frente a los problemas estructurales de las naciones empobrecidas y sumisas a la modernidad-colonialidad. Parte de este contexto, nos devela la complejidad de los tiempos que viven distintos países del mundo, pero en particular la fuerza de la racionalidad instrumental en función del proyecto/ empresa de la guerra y la máquina de la razón de orden político - mafiosa que cada vez controla las dimensiones cotidianas de la esfera pública, parte de este contexto expresa las dinámicas que contribuyen a la declive civilizatoria y multidimensional a lo largo siglo XXI. 
El libro escrito por tres profesores - investigadores Alberto Aziz, Enrique Lomelí y Jorge Alonso, a modo de coautores, los cuales coordinaron esfuerzos entre sí para darle fondo, forma y conjunto al presente texto titulado: "Tres miradas al México de hoy", simboliza una obra de gran envergadura dado la capacidad de analizar de forma crítico - propositiva los dilemas, avances, contradicciones y dificultades que coexisten al interior del sistema político e institucional mexicano, más allá de la narrativa oficial e institucionalizada del poder institucional propio de la investigaciones sobre las democracias en el campo epistémico de las ciencias sociales y políticas contemporáneas.

Los complejos sucesos que marcaron el siglo XX en México, reflejan situaciones de carácter profundo desde la emergencia y sublevación contra el autoritarismo institucional que operó de forma criminal contra el movimiento estudiantil del 68, al ser un punto de inflexión y disrupción de las narrativas históricas frente a la idea de arquitectura de los imaginarios políticos, que sirvieron de base para pensar qué tipo de sujetos políticos coexisten en la sociedad civil, debido a la influencia directa de los poderes privados que no responden a las necesidades y soluciones auténticas propias de la situación social y popular de los de abajo.

El primer ensayo, denominado "democratización y realineamiento político electoral", plantea la importancia de considerar elementos de orden analítico y sistémicos, basados en el interés estructural sobre la des-democratización, resultados, representación y partidocracia del régimen político - institucionalizado en México. La posibilidad de entender los cambios, procesos y resistencias que configuran las dinámicas y capacidades en función de la crítica a las instituciones, las cuales han sido permeadas por los anti-valores de la cultura e imaginario políticos propios de la corrupción, la deslegitimidad social y el control corporativo de los espacios públicos cada vez más alineados al sistema mundo - capitalista.

El segundo texto, nombrado "México: desafios del estancamiento (estabilizador) económico y social", señala el condicionante de analizar los atrasos y avances en distintos tiempos sobre las reformas estructurales emanadas de los grupos políticos ad hoc al modelo de la sociedad neoliberalizada y el Estado capitalista. Así pues, expone de forma concreta: datos, elementos y factores objetivados de la realidad social sobre la suspensión, 
avance y estabilización de un tipo de sistema político - burocrático acorde a la racionalidad de los grupos hegemónicos, en donde toma sentido la figura del "control" macroeconómico sin lograr resultados notorios en función del desarrollo economicista del Estado (neoliberal). La necesidad de reconocer el rol pasivo para ingresar de manera categórica en el ámbito internacional, es decir, el declive notorio de las últimas décadas sobre los procesos diplomáticos, de cooperación internacional y liderazgo multiláteras son campos cada vez alejados del proyecto paternalista propio de la cultura e imaginario tradicional, que no aportan soluciones a modo de oportunidades para pensar otra realidad más democrática y con justicia socio-política para las poblaciones en resistencia, al interior de sus territorios.

La última reflexión, es presentada por el antropólogo latinoamericano Jorge Alonso con un artículo profundo, titulado "México en movimiento en el cuarto lustro del siglo XXI", en donde describe de forma crítica las principales situaciones que coexisten y conllevan a una amplia desigualdad y diversidad sociocultural de la sociedad mexicana. La cual ha vivido acontecimientos que develan las complejas situaciones directa, indirecta y sistémica que son conducentes a la visión del posible Estado - nación en declive y la cooptación de los poderes políticos institucionales en función de un tipo de racionalidad privada, mecánica y criminal por parte de la figura detonante del narco-Estado y las fuerzas paraestatales que apuestan por violentar los proyectos autonómicos acorde a la cosmovisión de los pueblos indios en sus territorios.

Entre dichas problemáticas, aparece la fuerte oposición a los modelos corporativos basados en los réquiems neoliberales propios de la mercantilización de los espacios públicos y la des-democratización que implican los procesos políticos entre la ciudadanía, el gobierno y el Estado, parte de estas relaciones ha sido un factor estructural de conflicto debido a los complejos intereses individuales y colectivos del sujeto político.

Parte de las demandas colectivas que pusieron en jaque la pérdida de los procesos de control, soberanía y liberación por parte de los movimientos, colectivos, grupos y organizaciones anti-sistémicas, liberadoras y populares que denuncian de forma radical situaciones problemáticas como son: la reforma energética, el gasolinazo, la militarización estatal/territorial y la incongruente ley de seguridad fragmentada entre la racionalidad de los 
sectores políticos - corporativos y la fuerza de control/manipulación por parte del narcotráfico en la región.

En efecto, la obra descrita permite acercarse de forma intersubjetiva y crítica a una lectura sobre la complejidad de fenómenos que constituyen la realidad socio - política mexicana. Frente a este contexto, emerge la propuesta subalterna y de resistencia popular asumida por los pueblos indígenas, a través del Congreso Nacional Indígena (CNI) y el Concejo Indígena de Gobierno (CIG), que cuestionan desde una praxis ético - política de liberación, aquellas formas tradicionales del poder político y los instrumentos de control/dominación que históricamente han ejercido los grupos hegemónicos sobre los actores subalternos.

La emergencia de estos movimientos, organizaciones y colectivos de índole popular, femenino, étnico, anti-sistémico y subalternos, representa una serie de dinámicas de reconfiguración de la esfera pública desde la resistencia y el ejercicio sentipensante del sujeto orientado a la posibilidad de la democratización de la propia democracia en un plano horizontal, que permita la apertura a la legitimidad dialógica de la otredad en función de la praxis ética - liberadora propio de un modelo de ciudadanía sustantiva crítica - transformativa.

Sin embargo, los terribles sucesos que viven naciones sumidas a las dinámicas de la industria de la guerra y el modelo re-colonizador de dominación, despojo, hambruna y crímenes sistémicos contra los líderes, actores y grupos opositores a la visión desarrollista, extractivista y de saqueo generalizado sobre los bienes naturales. Parte de esta situación, son dilemas estructurales que existen en el panorama mexicano y que comparten otras naciones, el cual no es ajeno a la complejidad de fenómenos y problemáticas profundas que presencian los demás países de América Latina conducentes a la crisis civilizatoria de nuestros tiempos.

La necesidad de analizar de forma crítica la crisis sistémica de estos tiempos, sirve como un eslabón orientado a proponer alternativas desde abajo con respecto al complejo y turbulento siglo XXI, en el que coexisten los pueblos, grupos y actores subalternos que constituyen y apuestan por otro México, reflejan un imaginario fundamentado entre: dolor, rabia y esperanza por construir otros mundos posibles y necesarios más allá de la barbarie del Estado capitalista y la sociedad neoliberal precursora de violencias, miserias 
y desigualdades estructurales en los territorios. Así pues, toma sentido reconocer las demandas/luchas de aquella constelación de movimientos emergentes frente a los problemas cotidianos que instituyen un imaginario de sed de justicia por otra realidad popular y subalterna distinta a la actual.

Tal vez, la tarea de reconocer que la decadencia de los Estados - modernos y la privatización de los espacios públicos, demuestra la incapacidad de un sistema mundo - moderno/colonial que responde a las estructuras de control, violencia y dominación por parte de las élites en su proyecto re-colonizador de imponer una racionalidad de la muerte en función de los intereses del capital privado corporativo de carácter transnacional que va en contravía al buen vivir y el vivir bien en los territorios.

En últimas, el siglo XXI que trae consigo las nuevas formas de dominación sobre los países colonizados y sometidos a las estructuras neoliberales que configuran una condición de sumisión ante los intereses del capital privado, reflejan las estratagemas de dominación, miedo y terrorismo generalizado al interior de la sociedad civil, tal como lo simboliza, la terrible pandemia proveniente del SARS-CoV-2 (COVID-19), que devela el desmantelamiento de las gobiernos y la incapacidad estatal por garantizar las mínimas condiciones materiales e inmateriales que requiere la ciudadanía en tiempos de crisis civilizatoria.

Podríamos, pensar que el México de nuestra época se enfrenta a las diversas pandemias como son las violencias en los territorios, el racismo/ clasicismo frente a los poblados indígenas y el despojo de la vida, resultado de los intereses de los grupos hegemónicos en contubernio con los actores criminales que se incrustan al interior del narco-Estado y las estructuras moderno-coloniales del capital estatal y la sociedad individualizada, que cada vez normaliza la indiferencia hacia la otredad resultado de la miseria por sobrevivir ante la precariedad del capitalismo, que promueve así proyectos emergentes y subalternos geo-localizados en la importancia de luchar y apostar por otros mundos posibles, necesarios y urgentes al interior de las comunidades en resistencia, autonomía y liberación de sus tierras. 